\title{
Low loss silica-titania waveguide films
}

\author{
P. Karasiński, ${ }^{* 1}$ J. Jaglarz, ${ }^{2}$ and J. Mazur ${ }^{3}$ \\ ${ }^{I}$ Department of Optoelectronics, Silesian University of Technology, ul. B.Krzywoustego 2, 44-100 Gliwice, Poland \\ ${ }^{2}$ Institute of Physics, Cracow University of Technology, ul. Podchorązych 1, Kraków, Poland \\ ${ }^{3}$ Institute of Physics, Silesian University of Technology, ul. B.Krzywoustego 2, 44-100 Gliwice
}

Received March 3, 2010; accepted March 12, 2010; published March 31, 2010

\begin{abstract}
The paper presents research results on two-component waveguide films $\mathrm{SiO}_{2}: \mathrm{TiO}_{2}$ produced in sol-gel technology. The waveguide films were deposited on soda-lime glass substrates using the dip-coating method. For the produced waveguide films, the dispersion characteristics of the refractive index and of the extinction coefficient were determined. The AFM method was used to investigate the typology of waveguide film surfaces. The attenuation of waveguide films was determined using the streak method.
\end{abstract}

The integrated optics is based on waveguide films which are produced by various techniques, such as: ion exchange in glass [1], [2], methods of chemical vapour deposition (PECVD, LPCVD) [3] and the sol-gel method [4]-[7]. In chemical vapour deposition methods and in the sol-gel method, uniform waveguide films are produced whereof refractive index can be controlled within a wide range. Such methods can be applied to produce waveguide structures having high-contrast refractive indexes and low attenuation. The paper presents the research results involving two-component waveguide films $\mathrm{SiO}_{2}: \mathrm{TiO}_{2}$ produced in sol-gel technology. The waveguide films were deposited on soda-lime glass substrates using the dip-coating method. The properties of the waveguide films have been presented with a particular emphasis placed on their attenuation.

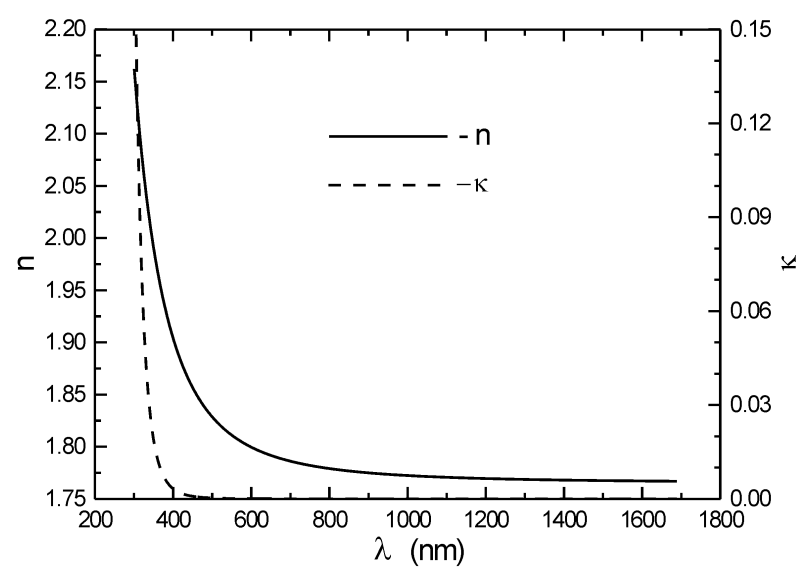

Fig.1 Complex refractive index of the silica-titania waveguide film

$$
\text { *E-mail: pawel.karasinski@polsl.pl }
$$

As the precursors of silica $\left(\mathrm{SiO}_{2}\right)$ and titania $\left(\mathrm{TiO}_{2}\right)$ we applied respectively tetraetoxysilane $\mathrm{Si}\left(\mathrm{OC}_{2} \mathrm{H}_{5}\right)_{4}$ (TEOS) and tetraetoxytitanate (TET). Ethanol $\left(\mathrm{C}_{2} \mathrm{H}_{5} \mathrm{OH}\right)$ was used as a homogenizing agent, and hydrochloric acid $\mathrm{HCl}$ as a catalyst. For the produced sols, the molar ratio TEOS:TET was 1. After the deposition of sols on glass substrates, the structures were heated at $500^{\circ} \mathrm{C}$ for $60 \mathrm{~min}$. The thickness of the produced waveguide films was controlled through a substrate withdrawal speed.

The dispersion characteristics of the films $\mathrm{SiO}_{2}: \mathrm{TiO}_{2}$ were determined with the application of the spectral ellipsometer Woollam M2000 ( $\lambda=200 \pm 1700 \mathrm{~nm})$. The dispersion characteristics of the refractive index $n$ and of the extinction coefficient $k$ are presented in Fig.1. These relations, and in particular the dispersion characteristic of the refractive index is indispensable in the designing process of planar elements or systems produced with the application of the presented waveguide films. Fig.2 presents the topography image of a waveguide film surface obtained with the use of an atomic force microscope AFM. The surface root mean square roughness determined for the whole area $1 \times 1 \mu \mathrm{m}^{2}$ was $\sigma_{r m s}$ $=0.225 \mathrm{~nm}$. Roughness is one of the basic parameters characterizing surface quality.

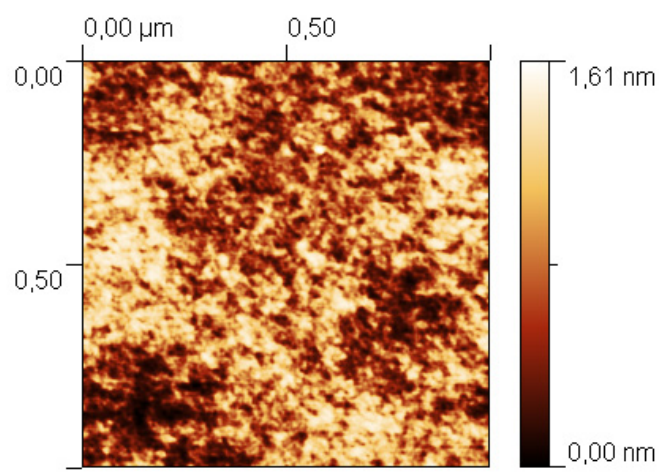

Fig.2 AFM image of the surface of a silica-titania waveguide film

Attenuation measurements were carried out using the streak method. The setup of such a measuring system is presented in Fig.3. Planar waveguides SW were excited using a prism coupler PC. A laser diode LD $(\lambda=677 \mathrm{~nm})$ 
was used as a light source. The polarization state of a light beam was determined using the polarizer $\mathrm{P}$ and rotator $\mathrm{R}$. The streak image of light scattered in the waveguide was recorded with a CCD camera coupled with a computer. Through the application of photo lens $\mathrm{OB}$ it was possible to illustrate the image of the whole observed waveguide on a camera chip.

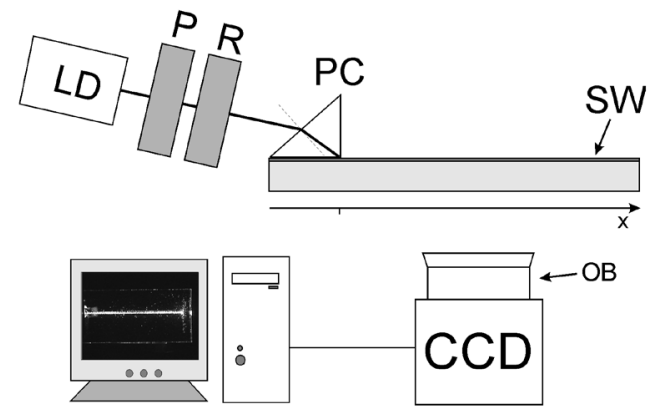

Fig.3 Schematic diagram of the measurement set-up. LD- laser diode $(\lambda=677 \mathrm{~nm}), \mathrm{P}$ - polarizer, $\mathrm{R}$ - rotator, $\mathrm{PC}$ - prism coupler, $\mathrm{SW}-$ slab waveguide, OB. - photo lens

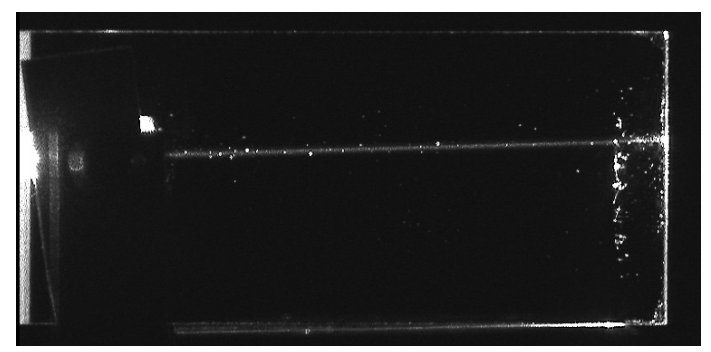

Fig.4 Scattered light streak from a silica-titania slab waveguide

Fig.4 presents an exemplary image of the excited waveguide, which was recorded in the measurement setup shown in Fig.3. We can distinctly observe a streak of scattered light. When the structure is uniform along the light propagation path, then the intensity distribution of the scattered light corresponds to the light intensity distribution in the waveguide along the propagation direction. In this way, basing on the intensity distribution of the scattered light along the waveguide, we can determine the waveguide attenuation. Fig. 5 presents the intensity distribution of the scattered light along the waveguide (Fig.4). By matching this distribution with the exponential relation $S(x)=S(0) \cdot \exp (-\mu x)$ (solid line on the picture) the loss coefficient $\mu$ was determined, from which the waveguide attenuation $\alpha=4.343 \mu$ was calculated. For the presented case we obtained the attenuation $\alpha=(0.18 \pm 0.07) \mathrm{dB} / \mathrm{cm}$. In the same way as above the attenuation for waveguides of different thickness was determined. The obtained results for the polarization TM are presented in Fig.6. We can observe the rise of attenuation with the rise of waveguide film thickness. The attenuation values are changing from $\sim 0.2 \mathrm{~dB} / \mathrm{cm}$ to $\sim 1.5 \mathrm{~dB} / \mathrm{cm}$. As for waveguide films of a high refractive index $(n \sim 1.8)$, these are very low attenuation values. In view of sensor applications, waveguide films of the thickness $d<200 \mathrm{~nm}$ are most attractive, and the ones presented here have the lowest attenuation. Detailed analysis involving the influence of surface roughness of a waveguide film on light scattering shows that the main

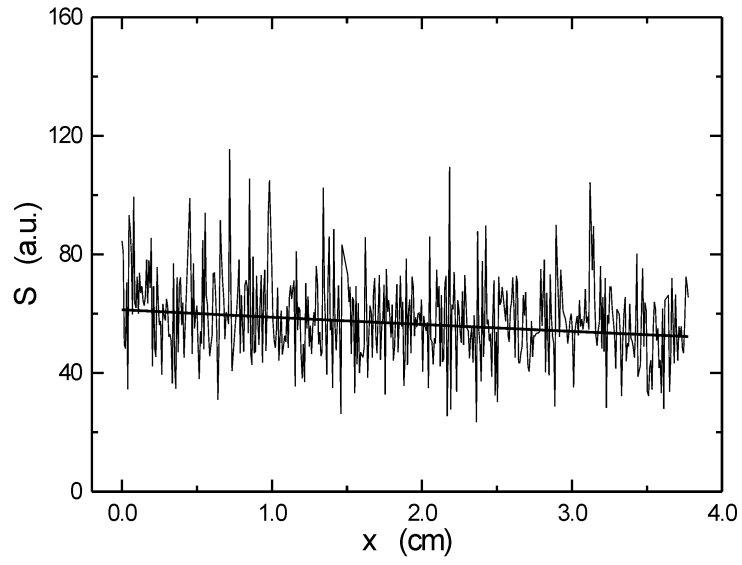

Fig. 5 Intensity distribution of scattered light along the waveguide

loss is affected by the dissipation on the boundary surface with the substrate. The attenuation is proportional to the square of $\sigma_{r m s}$ and to the power density on the surface, which is the source of light scattering [8]. Therefore, for the waveguide films of lower thickness $d$, the attenuation is rising with the rise of film thickness, since, at the same time, the power density is rising on the boundary surface of a waveguide film. For thicker films ( $d>200 \mathrm{~nm})$ stronger attenuation within the film volume is probably

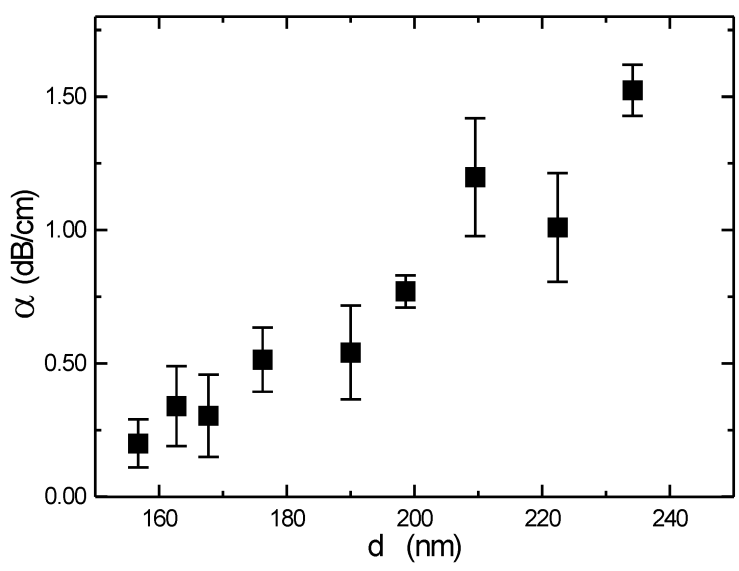

Fig.6 Influence of waveguide film thickness on the attenuation. TM polarization.

taking place. Such films are characterized by high stresses which result from film compression during the heating process. The said stresses may contribute to the creation of microcracks in the film structure. And for this reason, 
in the sol-gel technology of inorganic films $\mathrm{SiO}_{2}: \mathrm{TiO}_{2}$ we cannot produce single cracked free films of a thickness higher than 300nm [9].

The work is sponsored by the Polish Ministry of Science and High Education within Grant N 515057 $31 / 2432$.

\section{References}

[1] S.I. Najafi, Introduction to glass integrated optics (Boston, Artech House 1992).

[2] A.Opilski, R.Rogoziński, M.Błahut, P.Karasiński, K.Gut, Z.Opilski, Opt. Engin. 36, 1625 (1997).

[3] R.G.Heideman, P.V.Lambeck, Sens. Actuators B 61, 100 (1999).

[4] C.J.Brinker, G.W.Scherer, Sol-gel science, (San Diego, Academic Press, Inc. 1990).

[5] L.C.Klein, Sol-gel optics-processing and applications (Boston, Kluwer Academic Publisher, 1994).

[6] P.Karasiński, Opt. Appl. 34, 467 (2004).

[7] P.Karasiński P., Act. Phys. Pol. A, 116, 114 (2009).

[8] F.P.Payne, J.P.R.Lacey, Opt. Quantum Electron. 26, 977 (1994).

[9] R.R.A. Syms, Holmes, J. Non-Cryst. Solids 170, 223 (1994) 